\title{
Cytoreductive Surgery and Hyperthermic Intraperitoneal Chemotherapy in Younger Patients with Peritoneal Metastasis from Colorectal Cancer
}

\section{Haipeng Chen}

Cancer Hospital Chinese Academy of Medical Sciences

\section{Sicheng Zhou}

Cancer Hospital Chinese Academy of Medical Sciences

\section{Yujuan Jiang}

Cancer Hospital Chinese Academy of Medical Sciences

Zhaoxu Zheng

Cancer Hospital Chinese Academy of Medical Sciences

\section{Zheng Liu}

Cancer Hospital Chinese Academy of Medical Sciences

Qian Liu

Cancer Hospital Chinese Academy of Medical Sciences

Jianping Xu

Cancer Hospital Chinese Academy of Medical Sciences

Wei Pei ( $\nabla$ peiweifbwk@163.com )

Cancer Hospital Chinese Academy of Medical Sciences

Jianwei Liang

Cancer Hospital Chinese Academy of Medical Sciences

\section{Xishan Wang}

Cancer Hospital Chinese Academy of Medical Sciences

\section{Research}

Keywords: cytoreductive surgery, hyperthermic intraperitoneal chemotherapy, young patients, survival

Posted Date: October 11th, 2021

DOI: https://doi.org/10.21203/rs.3.rs-956314/v1

License: (1) (1) This work is licensed under a Creative Commons Attribution 4.0 International License.

Read Full License 


\section{Abstract}

Background Currently, few studies have evaluated effectiveness of cytoreductive surgery (CRS) and hyperthermic intraperitoneal chemotherapy (HIPEC) in young patients with peritoneal metastasis (PM) of colorectal cancer (CRC) origin.

Method Clinicopathological characteristics, perioperative data and survival outcomes in young patients, defined as being 50 years or less ( $n=23$ ), performing CRS+HIPEC between June 2017 to June 2019 were reviewed and compared with older patients, defined as aged over 50 years $(n=47)$.

Results Compared with older patients, young patients were more likely to present with PM at the time of diagnosis $(78.3 \%$ vs $51.1 \%, P=0.029)$ and exhibit a mucinous and signet-ring histology $(60.9 \%$ vs $29.8 \%$, $P=0.013$ ). The cancer-specific survival (CSS) after CRS+HIPEC in two groups are similar. On multivariate Cox regression, rectal origin $(\mathrm{HR}, 2.51,95 \% \mathrm{Cl}, 1.11-5.67 ; P=0.027)$ and mucinous/signet adenocarcinoma (HR, 2.20,95\% Cl, 1.02-4.74; $P=0.044$ ) were independent risk factors for poor CSS.

Conclusion Younger patients (aged $\leq 50$ years) with PM of CRC origin presented more often with synchronous PM than older patients. Although tend to exhibit a aggressive nature, they derive similar benefit from CRS+HIPEC as older patients.

\section{Introduction}

Colorectal cancer (CRC) is the third most common malignant tumor in the world, with approximately 1.8 million newly diagnosed cases in $2018^{[1]}$. The prevalence of colonoscopy and improved awareness of cancer prevention have led to a decline in the overall incidence of colorectal cancer, while the incidence in young patients has increased by about $2 \%$ per year over the past decade ${ }^{[2-4]}$. Recently, an epidemiological study found that the incidence of CRC only increased in young adults (20-49 years) based on populations in nine high-income countries across three continents ${ }^{[5]}$. Meanwhile, compared with the elderly, more patients with young-onset CRC presented with distant metastases at the time of diagnosis, due to different biological behavior and lower suspicion of $\mathrm{CRC}^{[6,7]}$. Currently, the prognosis of young-onset CRC patients remains controversial ${ }^{[8-10]}$.

The peritoneum metastasis (PM) is the third most common site of colorectal cancer metastasis following liver metastasis and lung metastasis, and is generally considered as end-stage disease. Synchronous PM has been reported in $8-15 \%$ of patients with CRC, while the rate of metachronous PM can reach $20-50 \%$ [11]. For CRC patients with PM, traditional methods usually adopt palliative surgery and systemic chemotherapy, and the median survival time is only 5-7 months ${ }^{[12]}$. In recent years, Cytoreductive Surgery (CRS) combined with hyperthermic intraperitoneal chemotherapy (HIPEC) has shown good clinical efficacy in the comprehensive treatment of various malignant peritoneal diseases, and can prolong the long-term survival in appropriately specific CRS patients ${ }^{[13,14]}$. However, as a special population, youngonset CRC patients have unique molecular profile and aggressive nature, and whether they can also 
benefit from CRS+HIPEC is currently rarely reported in the literature ${ }^{[15-18]}$. Therefore, the purpose of this study was to investigate the clinicopathological characteristics of young-onset CRC patients( $\leq 50$ years) with PM, and to evaluate the long-term therapeutic effect of CRS+HIPEC.

\section{Patients And Method}

This study was a single-center retrospective study, with patients characteristics obtained from a prospectively collected database. From June 2017 to June 2019, all consecutive CRC patients presenting PM who had performed CRS and HIPEC at the National Cancer Center were enrolled in this study after the approval of our institutional multidisciplinary review committee. The inclusion criteria are as follows: (1) Age 18-75 years old; (2) Pathologically confirmed as colorectal adenocarcinoma; (3) Eastern Cooperative Group (ECOG) score $\leq 1$. The exclusion criteria were as follows: (1) Presented with liver and lung and other distant metastases;(2) History of other malignant tumors; (3) Malignant tumor of appendiceal origin.

All patients were grouped according to age at the time of diagnosis of CRC, and two cohorts were created: $\leq 50$ years and 51-75 years. All patients underwent preoperative workup to rule out extra-abdominal disease, including laboratory examinations, abdominal contrast-enhanced computed tomography (CT), and pelvic magnetic resonance imaging (MRI). The final comprehensive treatment strategy was made by multidisciplinary team that incorporated radiologists and medical and surgical oncologists. According to the Sugarbaker/Jacquet classification ${ }^{[19,20]}$, the extent of PM was assessed using the peritoneal cancer index (PCI) and the completeness of CRS was evaluated by the completeness of cytoreduction score (CC score).

The ethics committee of the National Cancer Center/Cancer Hospital, Chinese Academy of Medical Sciences and Peking Union Medical College approved this study. Prior written informed consent was obtained from all study participants.

\section{Surgical Procedure}

The surgical technique of CRS+HIPEC has been described previously ${ }^{[21,22]}$. Brief, various peritonectomy was selected depending on the the location of the PM, and intraperitoneal organ resection was performed according to the degree of tumor invasion. After cytoreduction, a closed HIPEC procedure was carried out with two chemotherapeutic regimens in present study: Oxaliplatin $\left(200 \mathrm{mg} / \mathrm{m}^{2}\right)$ and raltitrexed $\left(4 \mathrm{mg} / \mathrm{m}^{2}\right)$ with or without lobaplatin $\left(50 \mathrm{mg} / \mathrm{m}^{2}\right)$. A mixed solution of chemotherapy agents and $3 \mathrm{~L}$ of saline solution was infused in peritoneal cavity for $60 \mathrm{~min}$ at $43^{\circ} \mathrm{C}$. After that, two more same HIPEC procedures were carried out again on the second and fourth days after surgery in the ward.

\section{Statistical analysis}


Data were compared and analyzed using SPSS 24.0 software (IBM, Armonk, NY, USA). Categorical variables were expressed as percentages frequencies and compared by the $\chi 2$ test or Fisher's exact test as appropriate. Continuous variables were expressed as the mean \pm standard deviation and using Student's t-test or the Mann-Whitney U test. Overall survival (OS) was calculated as the time from the first CRS+HIPEC to death due to tumor or July 31, 2020, whichever came first. Disease-free survival (DFS) refers to the time from CRS+HIPEC to appearance of obvious evidence of recurrence. The survival analysis was performed by Kaplan-Meier methods and compared by log-rank test. Variables yielded a $P$ value $<0.05$ in the univariate analysis were further included into the multivariate analysis to identify independent predictors of OS and DFS. A $P$ value $<0.05$ was considered statistically significant.

\section{Results}

A total of 70 patients who performed CRS+HIPEC for PM of CRC origin were included in present study, 23 of whom were $\leq 50$ years old. The clinicopathological characteristics are listed in Table 1. There are 39 males and 31 females in the whole group, with an average age of $54.5 \pm 11.6$ years. The proportion of younger patients complicated with peritoneal metastasis at the initial diagnosis of colon cancer is significantly higher $(78.3 \%$ vs $51.1 \%, P=0.029)$. Notably, a higher proportion of younger patients pathologically confirmed mucinous/signet adenocarcinoma ( $60.9 \%$ vs $29.8 \%, P=0.013)$. Comparison of other clinical characteristics, such as BMI, preoperative chemotherapy, site of original, adjuvant chemotherapy, BRAF status, MSI, were all similar ( $P>0.05)$. 
Table 1

The clinicopathological characteristics of 70 patients underwent CRS/HIPEC

\begin{tabular}{|c|c|c|c|c|}
\hline Variables & $\begin{array}{l}\text { Total } \\
(n=70)\end{array}$ & $\begin{array}{l}\text { Aged } \leq 50 \\
\text { years } \\
(n=23)\end{array}$ & $\begin{array}{l}\text { Aged > } 50 \\
\text { years } \\
(n=47)\end{array}$ & $P$ \\
\hline Age (years, mean $\pm S D$ ) & $\begin{array}{l}54.5 \pm \\
11.6\end{array}$ & $40.9 \pm 6.9$ & $61.2 \pm 6.7$ & $<0.001$ \\
\hline Gender & & & & 0.677 \\
\hline Male & $39(55.7)$ & $12(52.2)$ & $27(57.4)$ & \\
\hline Female & $31(44.3)$ & $11(47.8)$ & $20(42.6)$ & \\
\hline $\mathrm{BMI}\left(\mathrm{Kg} / \mathrm{m}^{2}\right)$ & $22.7 \pm 3.6$ & $22.4 \pm 2.4$ & $23.1 \pm 2.8$ & 0.432 \\
\hline Preoperative chemotherapy & & & & 0.557 \\
\hline Presence & $30(42.9)$ & $11(47.8)$ & $19(40.4)$ & \\
\hline Absence & $40(57.1)$ & $12(52.2)$ & $28(59.6)$ & \\
\hline Presentation of PM & & & & 0.029 \\
\hline Synchronous & $42(60.0)$ & $18(78.3)$ & $24(51.1)$ & \\
\hline Metachronous & $28(40.0)$ & $5(21.7)$ & $23(48.9)$ & \\
\hline Site of original (\%) & & & & 0.527 \\
\hline Colon & $52(74.3)$ & $16(69.6)$ & $36(76.6)$ & \\
\hline Rectum & $18(25.7)$ & $7(30.4)$ & $11(23.4)$ & \\
\hline Preoperative CEA level $(n g$, mean \pm SD) & $\begin{array}{l}31.9 \pm \\
61.5\end{array}$ & $36.9 \pm 71.6$ & $31.6 \pm 61.7$ & 0.782 \\
\hline $\begin{array}{l}\text { Preoperative CA19-9 level (ng, mean } \pm \\
\text { SD) }\end{array}$ & $\begin{array}{l}75.4 \pm \\
93.3\end{array}$ & $90.1 \pm 106.6$ & $70.1 \pm 92.3$ & 0.491 \\
\hline Histology (\%) & & & & 0.013 \\
\hline Adenocarcinoma & $43(61.4)$ & $9(39.1)$ & $33(70.2)$ & \\
\hline Mucinous/signet & $27(38.6)$ & $14(60.9)$ & $14(29.8)$ & \\
\hline Adjuvant chemotherapy & & & & 0.232 \\
\hline Presence & $55(78.6)$ & $20(87.0)$ & $35(74.4)$ & \\
\hline Absence & $15(21.4)$ & $3(13.0)$ & $12(25.6)$ & \\
\hline BRAF status & & & & 0.859 \\
\hline Mutation & $13(18.6)$ & $4(17.4)$ & $9(19.1)$ & \\
\hline
\end{tabular}




\begin{tabular}{|lllll|}
\hline Variables & $\begin{array}{l}\text { Total } \\
(\mathbf{n = 7 0 )}\end{array}$ & $\begin{array}{l}\text { Aged } \leq \mathbf{5 0} \\
\text { years } \\
(\mathbf{n = 2 3 )}\end{array}$ & $\begin{array}{l}\text { Aged }>\mathbf{5 0} \\
\text { years } \\
(\mathbf{n = 4 7 )}\end{array}$ & $P$ \\
\hline No mutation & $57(81.4)$ & $19(82.6)$ & $38(80.8)$ & \\
\hline MSI & & & & 0.615 \\
\hline MSI-H & $8(11.4)$ & $2(8.7)$ & $6(12.8)$ & \\
\hline MSS & $62(88.6)$ & $21(91.3)$ & $41(87.2)$ & \\
\hline
\end{tabular}

The perioperative data are presented in Table 2. The mean PCl score was $11.1 \pm 6.0$ for young patients and $11.8 \pm 6.5$ for older patients $(P=0.536)$. The proportion of patients who achieved complete cytoreductive surgery (CC $0-1)$ was comparable in both groups $(69.6 \%$ vs $68.1 \%, P=0.900)$. Mean number of organs resection also were similar (2.2 vs. $1.9, P=0.401)$. Following the operation and within 30 days, 8 patients (34.8\%) developed postoperative complications in age $\leq 50$ group, and 17 (36.2\%) in age 51-65 group ( $P=0.909$ ). Comparison of other perioperative indicators, such as operation time, estimated blood loss, postoperative complication rates (grade $3-4)$, and total hospital days, were all similar $(P>0.05)$. 
Table 2

The perioperative data of 70 patients underwent CRS/HIPEC

\begin{tabular}{|c|c|c|c|c|}
\hline Variables & $\begin{array}{l}\text { Total } \\
(n=70)\end{array}$ & $\begin{array}{l}\text { Aged } \leq 50 \\
\text { years } \\
(n=23)\end{array}$ & $\begin{array}{l}\begin{array}{l}\text { Aged }>50 \\
\text { years }\end{array} \\
(n=47)\end{array}$ & $P$ \\
\hline Operative method & & & & 0.799 \\
\hline Laparoscopic surgery & $14(20.0)$ & $5(21.7)$ & $9(19.1)$ & \\
\hline Open surgery & $56(80.0)$ & $18(78.3)$ & $38(80.9)$ & \\
\hline \multicolumn{5}{|l|}{ HIPEC regimen } \\
\hline Lobaplatin+Oxaliplatin+Raltitrexed & $32(45.7)$ & $12(52.2)$ & $20(42.6)$ & \\
\hline Oxaliplatin+Raltitrexed & $38(54.3)$ & $11(47.8)$ & $27(57.4)$ & \\
\hline PCl score & $11.1 \pm 6.0$ & $11.8 \pm 6.5$ & $11.0 \pm 5.4$ & 0.536 \\
\hline Operation time (min, mean \pm SD) & $256.9 \pm 66.4$ & $261.5 \pm 68.7$ & $255.9 \pm 66.2$ & 0.450 \\
\hline Estimated blood loss $(\mathrm{ml}$, mean \pm SD) & $\begin{array}{l}122.1 \pm \\
109.2\end{array}$ & $109.1 \pm 101.9$ & $127.2 \pm 104.7$ & 0.516 \\
\hline Presence of ascites & $30(42.9)$ & $8(34.8)$ & $22(46.8)$ & 0.340 \\
\hline CC score & & & & 0.900 \\
\hline CC $0-1$ & $48(68.6)$ & $16(69.6)$ & $32(68.1)$ & \\
\hline CC 2-3 & $22(31.4)$ & $7(30.4)$ & $15(31.9)$ & \\
\hline Number of organs resection & $2.0 \pm 1.1$ & $2.2 \pm 1.2$ & $1.9 \pm 1.1$ & 0.401 \\
\hline $\begin{array}{l}\text { Postoperative Complications (grade 1- } \\
\text { 4) }\end{array}$ & $25(35.7)$ & $8(34.8)$ & $17(36.2)$ & 0.909 \\
\hline $\begin{array}{l}\text { Postoperative Complications (grade 3- } \\
\text { 4) }\end{array}$ & $17(24.3)$ & $5(21.7)$ & $12(25.5)$ & 0.728 \\
\hline Total hospital stay (day, mean \pm SD) & $14.6 \pm 5.3$ & $14.4 \pm 5.2$ & $15.1 \pm 5.4$ & 0.220 \\
\hline Re-operation & $2(2.9)$ & $0(0)$ & $2(4.3)$ & 0.810 \\
\hline Mortality & $0(0)$ & $0(0)$ & $0(0)$ & 1.000 \\
\hline
\end{tabular}

\section{Survival Analyses}

The median follow-up period was 21.0 (range, 3-33) months. The median CCS since diagnosis were 26.0 months (95\% Cl, 20.7-31.3 months). The estimated 1-, 2- and 3-year CCS rates for the entire cohort were 
$81.3 \%, 58.0 \%$, and $42.9 \%$, respectively. CCS of patients aged $\leq 50$ years who underwent CRS+HIPEC treated for PM of CRC origin are similar to those of patients aged 51-65 years (Figure 1).

On the Cox univariate regression analysis, factors found to be associated with reduced CCS were increasing $\mathrm{PCl}(\mathrm{HR} 1.08,95 \% \mathrm{Cl} 1.03-1.14, \mathrm{P}=0.004)$, rectal origin $(\mathrm{HR} 2.58,95 \% \mathrm{Cl} 1.24-5.37, \mathrm{P}=0.011)$, mucinous (HR 2.13, 95\% Cl 1.05-4.33, P = 0.036)., and incomplete cytoreduction (HR 2.99, 95\% Cl 1.47$6.10, \mathrm{P}=0.003)$. On multivariate Cox regression, rectal origin $(\mathrm{HR}, 2.51,95 \% \mathrm{Cl}, 1.11-5.67 ; P=0.027)$ and mucinous/signet adenocarcinoma (HR, 2.20,95\% Cl, 1.02-4.74; $P=0.044)$ were independent risk factors for poor DFS(Table 3).

Table 3

Univariate and multivariate Cox regression analysis of cancer-specific survival and disease-free survival in 70 patients after CRS/HIPEC

\begin{tabular}{|c|c|c|c|c|}
\hline \multirow[t]{3}{*}{ Variables } & \multicolumn{4}{|c|}{ Cancer-specific survival } \\
\hline & \multicolumn{2}{|c|}{ Univariate analysis } & \multicolumn{2}{|c|}{ Multivariate analysis } \\
\hline & $\mathrm{HR}(95 \% \mathrm{Cl})$ & $\mathbf{P}$ & $\mathrm{HR}(95 \% \mathrm{Cl})$ & $P$ \\
\hline Gender: male/female & $1.20(0.59-2.44)$ & 0.606 & & \\
\hline Age ( $50-65$ years $/ \leq 50$ years $)$ & $1.53(0.70-3.33)$ & 0.284 & & \\
\hline Preoperative chemotherapy (no/yes) & $0.53(0.20-1.38)$ & 0.191 & & \\
\hline Synchronous/metachronous & $1.03(0.51-2.08)$ & 0.942 & & \\
\hline Site of original (rectum/colon) & $2.58(1.24-5.37)$ & 0.011 & $2.51(1.11-5.67)$ & 0.027 \\
\hline Histology (adenocarcinoma/mucinous) & $2.13(1.05-4.33)$ & 0.036 & $2.20(1.02-4.74)$ & 0.044 \\
\hline Preoperative CEA level & $1.00(0.99-1.01)$ & 0.281 & & \\
\hline Preoperative CA19-9 level & $1.00(0.99-1.01)$ & 0.232 & & \\
\hline HIPEC regimen (lobaplatin/non-lobaplatin) & $1.50(0.73-3.06)$ & 0.268 & & \\
\hline Presence of ascites (yes/no) & $1.53(0.75-3.10)$ & 0.241 & & \\
\hline PCl score & $1.08(1.03-1.14)$ & 0.004 & $1.03(0.96-1.11)$ & 0.349 \\
\hline CC score $(0-1 / 2-3)$ & $2.99(1.47-6.10)$ & 0.003 & $1.73(0.70-4.27)$ & 0.231 \\
\hline Grade 3-4 Postoperative complication & $1.11(0.50-2.49)$ & 0.801 & & \\
\hline
\end{tabular}

\section{Discussion}

Three consecutive years of tumor epidemiological data in the United States show that the overall incidence of CRC is on the decline, but an rising incidence of young-onset CRC was noted ${ }^{[2-4]}$. Due to different biological behavior and lower suspicion of CRC, young patients are more often present 
advanced stage at diagnosis ${ }^{[6,7]}$. In present study, we found that more young-onset patients present with PM at the initial diagnosis, while older patients more likely develop metachronous PC. This finding is mainly attributed to the lack of sufficient health care awareness and lower suspicion of CRC in younger age group. A cohort study in the United States found that the median time from the onset of symptoms to treatment for rectal patients younger than 50 years old was significantly longer than that of patients older than 50 years old (217 vs 29.5 days) ${ }^{[23]}$. Therefore, it is necessary to universally recommend screening for patient aged $<50$ years who was at elevated risk of CRC because of high risk personal and family history.

Different molecular changes contribute to the heterogeneity of young-onset CRC, which often exhibit more aggressive nature compared with late-onset $\mathrm{CRC}^{[25]}$. National Cancer Database showed that youngonset patients are typically associated with poor pathological features such as mucinous and signet ring carcinoma. Our study also showed that patients in younger age group more likely present mucinous/signet adenocarcinoma (60.9\% vs $29.8 \%, P=0.013)$.

Few studies have been reported on the survival outcomes of CRS/HIPEC in treatment for PM of CRC origin in younger patients ${ }^{[18,27]}$. Young patients tend to have strong aggressive biological profile due to a higher incidence of signet ring cells and mucinous adenocarcinoma, ant they more likely presented with advanced stage at the time of diagnosis, so in theory they tend to have a poor prognosis. However, our study demonstrated that OS and DFS of patients aged $\leq 50$ years who underwent CRS+HIPEC treated for PM of CRC origin are similar to those of patients aged over 50 years. Multivariate analysis showed that rectal origin (HR, 2.51,95\% $\mathrm{Cl}, 1.11-5.67 ; P=0.027)$ and mucinous/signet adenocarcinoma (HR, 2.20, $95 \% \mathrm{Cl}, 1.02-4.74 ; P=0.044)$ were independent risk factors for poor CCS. A subgroup analysis of 237 patients with CRC conducted by Dhir and colleagues revealed that 37 patients aged 15-39 years underwent CRS+HIPEC, and no difference in median survival was found compared with the older controls (28.7 vs 38.9 months, $P=0.509)^{[18]}$, which is basically consistent with our results. CRS+HIPEC is a lifethreatening procedure, and the incidence of postoperative complications in older patients is higher, which affects subsequent treatment. In addition, younger patients tend to receive more radical treatments. The above-mentioned reasons may be responsible for similar long-term survival. However, Solomon et al. analyzed the survival outcomes of 98 patients with PM of CRC origin in different ages ( $<50$ years or $\geq 50$ years) after CRS+HIPEC, their results showed that patients $<50$ years survived significantly longer than older controls, both from time of initial diagnosis and from CRS/HIPEC. The reason for the different results may be that patients over 65 years old were not included in this study, because the proportion of elderly patients over 65 years old was relatively low, and such patients have more organic diseases. Relevant literature reported that patients with PM of CRC origin over 65 years old benefited less from CRS+HIPEC ${ }^{[28]}$.

There were several limitations in this study. The present study is a retrospective analysis of only 70 patients from a single center database, retrospective cohort design and relatively small numbers potentially generating selection bias. However, we believe our results are reliable and data collection was complete. Multi-center large sample studies are required to further verify our conclusions. 
In conclusion, younger patients (aged $\leq 50$ years) with PM of CRC origin presented more often with synchronous PM than older patients (aged over 50 years). Although tend to exhibit a aggressive nature, they derive similar benefit from CRS+HIPEC as older patients. There should be a raise in awareness of the young-onset CRC, especially for those with high risk personal and family history.

\section{Declarations}

\section{Ethics approval}

The ethics committee of the National Cancer Center/Cancer Hospital, Chinese Academy of Medical Sciences and Peking Union Medical College approved this study. Prior written informed consent was obtained from all study participants.

\section{Consent to participate}

Not Applicable.

\section{Consent for publication}

Not Applicable.

\section{Availability of data and materials}

The datasets generated and/or analysed during the current study are not publicly available due to the data is confidential patient data but are available from the corresponding author on reasonable request.

\section{Competing interests}

The authors declare that they have no competing interests.

\section{Funding}

This work was supported by Capital's Funds for Health Improvement and Research (2016-2-4022). The funding source didn't involve the preparation of the article.

\section{Authors' contributions}

Contributions: (I) conception and design: JPX, SCZ, and WP; (II) administrative support: JPX and XSW and JWL; (III) provision of study materials or patients: YJJ and ZXZ and QL and ZL ; (IV) collection and assembly of data: SCZ and HPC; (V) data analysis and interpretation: SCZ and HPC. All authors read and approved the final manuscript.

\section{Acknowledgements}


Not applicable.

\section{References}

1. Bray F, Ferlay J, Soerjomataram I, et al. Global cancer statistics 2018: GLOBOCAN estimates of incidence and mortality worldwide for 36 cancers in 185 countries. CA Cancer J Clin. 2018;68(6):394-424.

2. Siegel RL, Miller KD, Jemal A, Cancer statistics. 2018. CA Cancer J Clin 2018;68(1):7-30.

3. Araghi M, Soerjomataram I, Bardot A, et al. Changes in colorectal cancer incidence in seven highincome countries: a population-based study. Lancet Gastroenterol Hepatol. 2019;4(7):511-8.

4. Vuik FE, Nieuwenburg SA, Bardou M, et al. Increasing incidence of colorectal cancer in young adults in Europe over the last 25 years. Gut. 2019;68(10):1820-6.

5. Siegel RL, Torre LA, Soerjomataram I, et al. Global patterns and trends in colorectal cancer incidence in young adults. Gut. 2019;68(12):2179-85.

6. Ballester V, Rashtak S, Boardman L. Clinical and molecular features of young-onset colorectal cancer. World J Gastroenterol. 2016;22(5):1736-44.

7. Silla IO, Rueda D, Rodríguez Y, et al. Early-onset colorectal cancer: a separate subset of colorectal cancer. World J Gastroenterol. 2014;20(46):17288-96.

8. Abdelsattar ZM, Wong SL, Regenbogen SE, et al. Colorectal cancer outcomes and treatment patterns in patients too young for average-risk screening. Cance. 2016;122(6):929-34.

9. Goldvaser H, Purim O, Kundel Y, et al. Colorectal cancer in young patients: is it a distinct clinical entity? Int J Clin Oncol. 2016;21(4):684-95.

10. Vatandoust S, Price TJ, Ullah S, et al. Metastatic Colorectal Cancer in Young Adults: A Study From the South Australian PopulationBased Registry. Clin Colorectal Cancer. 2016;15(1):32.

11. Sadeghi B, Arvieux C, Glehen O, et al. Peritoneal carcinomatosis from non-gynecologic malignancies: results of the EVOCAPE 1 multicentric prospective study. Cancer. 2000;88(2):358-63.

12. Chen $\mathrm{W}$, Zheng $\mathrm{R}$, Zeng $\mathrm{H}$, et al. The updated incidences and mortalities of major cancers in China, 2011. Chin J Cancer. 2015;34(11):502-7.

13. Cashin $\mathrm{PH}$, Mahteme $\mathrm{H}$, Spang $\mathrm{N}$, et al. Cytoreductive surgery and intraperitoneal chemotherapy versus systemic chemotherapy for colorectal peritoneal metastases: a randomised trial. Eur $\mathrm{J}$ Cancer. 2016;53:155-62.

14. Glehen $\mathrm{O}$, Kwiatkowski F, Sugarbaker PH, et al. Cytoreductive surgery combined with perioperative intraperitoneal chemotherapy for the management of peritoneal carcinomatosis from colorectal cancer: a multi-institutional study. J Clin Oncol. 2004;22:3284-92.

15. Solomon D, DeNicola NL, Feferman Y, et al. More Synchronous Peritoneal Disease but Longer Survival in Younger Patients with Carcinomatosis from Colorectal Cancer Undergoing Cytoreductive Surgery and Hyperthermic Intraperitoneal Chemotherapy. Ann Surg Oncol. 2019;26(3):845-51. 
16. Hayes-Jordan A, Green H, Lin H, et al. Cytoreductive surgery and hyperthermic intraperitoneal chemotherapy (HIPEC) for children, adolescents, and young adults: the first 50 cases. Ann Surg Oncol. 2015;22:1726-32.

17. Oyeniyi J, Wu J, Liu D, et al. Treatment of carcinomatosis using cytoreductive surgery and hyperthermic intraperitoneal chemotherapy in adolescents and young adults. Am J Surg. 2015;209:610-5.

18. Dhir M, Ramalingam L, Shuai Y, et al. Cytoreductive surgery and hyperthermic intraperitoneal chemoperfusion in adolescent and young adults with peritoneal metastases. Ann Surg Oncol. 2017;24:875-83.

19. Jacquet $P$, Sugarbaker PH. Clinical research methodologies in diagnosis and staging of patients with peritoneal carcinomatosis. Cancer Treat Res. 1996;82:359-74.

20. Sugarbaker PH. Peritonectomy procedures. Ann Surg. 1995;221(1):29-42.

21. Pei W, Zhou S, Zhang J, et al. Lobaplatin-Based Hyperthermic Intraperitoneal Chemotherapy for Patients with Peritoneal Metastasis from Appendiceal and Colorectal Cancer: Safety and Efficacy Profiles. Cancer Manag Res. 2020;24(12):12099-110.

22. Zhou S, Feng Q, Zhang J, et al. High-grade postoperative complications affect survival outcomes of patients with colorectal Cancer peritoneal metastases treated with Cytoreductive surgery and Hyperthermic Intraperitoneal chemotherapy. BMC Cancer. 2021;21(1):41.

23. Provenzale D, Gupta S, Ahnen DJ, et al. NCCN guidelines insights: colorectal cancer screening, version 1.2018. J Natl Compr Canc Netw. 2018;16:939-49.

24. Rex DK, Boland CR, Dominitz JA, et al. Colorectal cancer screening: recommendations for physicians and patients from the U.S. Multi-Society Task Force on Colorectal Cancer. Am J Gastroenterol. 2017;112:1016-30.

25. Silla IO, Rueda D, Rodríguez Y, et al. Early-onset colorectal cancer: a separate subset of colorectal cancer. World J Gastroenterol. 2014;20:17288-96.

26. Ahnen DJ, Wade SW, Jones WF, et al. The increasing incidence of young-onset colorectal cancer: a call to action. Mayo Clin Proc. 2014;89:216-24.

27. Solomon D, DeNicola NL, Feferman Y, et al. More Synchronous Peritoneal Disease but Longer Survival in Younger Patients with Carcinomatosis from Colorectal Cancer Undergoing Cytoreductive Surgery and Hyperthermic Intraperitoneal Chemotherapy. Ann Surg Oncol. 2019;26(3):845-51.

28. López-López V, Cascales-Campos PA, Schneider MA, et al. Cytoreductive surgery and hyperthermic intraperitoneal chemotherapy (HIPEC) in elderly patients. A systematic literature review. Surg Oncol. 2016;25(4):378-84.

\section{Figures}




\section{Cancer-specific survival curve}

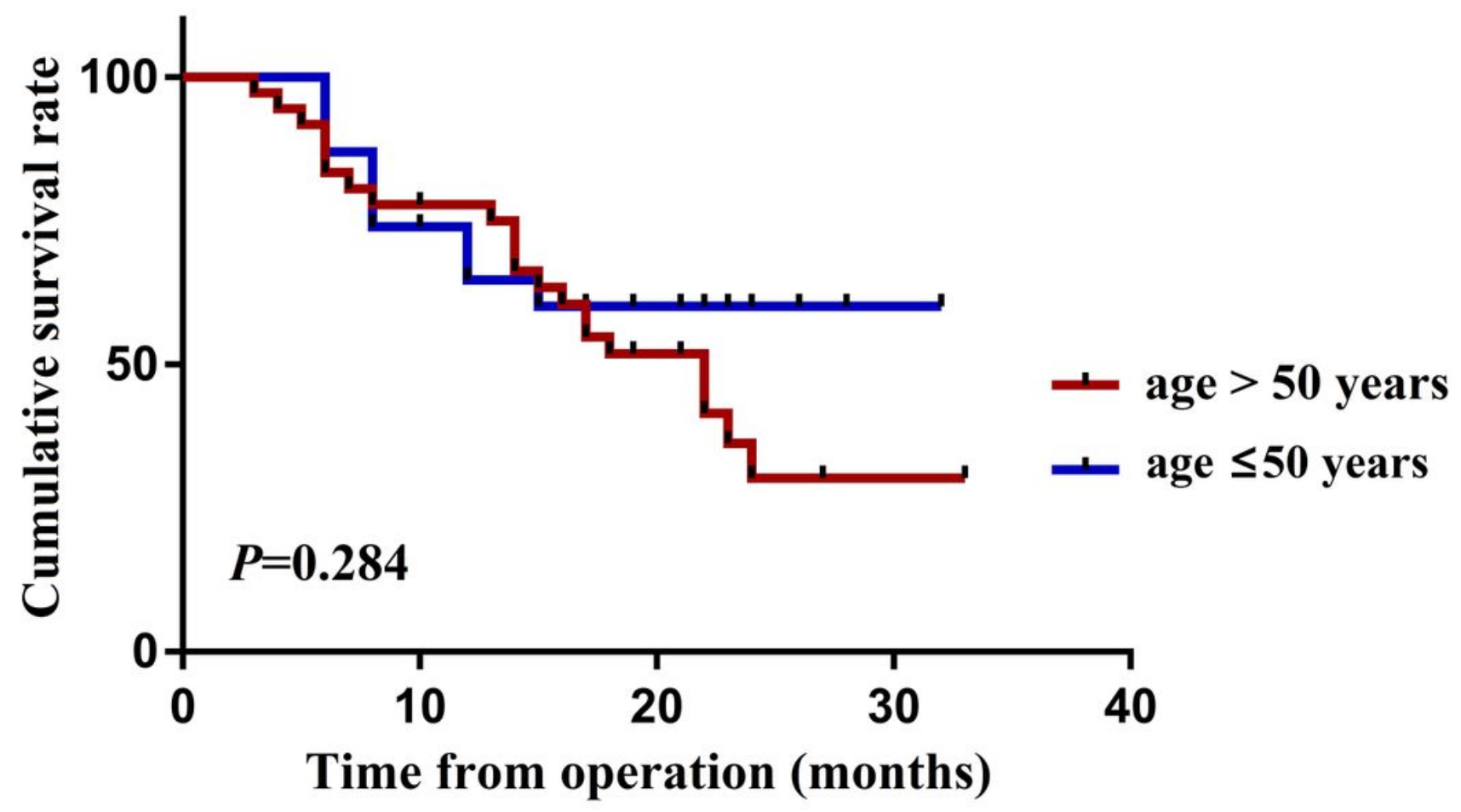

Figure 1

CCS of patients aged $\leq 50$ years who underwent CRS+HIPEC treated for PM of CRC vs those of patients aged over 50 years 